\title{
LXXX. Description of an Improved screw wrench to fit different-sized nuts or heads of screws
}

\author{
Mr. Wm. Barlow
}

To cite this article: Mr. Wm. Barlow (1809) LXXX. Description of an Improved screw wrench to fit different-sized nuts or heads of screws, Philosophical Magazine Series 1, 33:134, 450-451, DOI: $10.1080 / 14786440908562903$

To link to this article: http://dx.doi.org/10.1080/14786440908562903

曲 Published online: 18 May 2009.

Submit your article to this journal $\lceil\pi$

ЏII Article views: 2

Q View related articles $\square$ 
slip is cut into a segment of a circle struck from the hinges on which it turns. The perspective view in fig. 1 shows that this contrivance, applied to any door, will not offend the eye, as it can scarcely be distinguished from an ordinary door. $K$, fig. 1 , shows the concave semicircle of the piece of wood fastened to the door-case, in which the semicircular end of the $\operatorname{slip} e$ is to be received.

\section{Description of an Improved Screw Wrench to fit} different-sized Nuts or Heads of Screws. By Mr. WM. Barlow, of His Majesty's Dock Yard, Portsmouth*.

\section{SIR,}

$P_{\text {ERmit me to make a few observations on a shifting screw }}$ wrench of my invention, which I beg leave to lay before the Society of Arts, \&cc., through the hands of Mr. Brunel, inventor of the block machinery here.

I have found, frim long experience, the imperfections of the various wrenches in common use, for the screw heads and nuts of engines in general, which are often materially injured for want of an instrument which would fit variety of sizes, and be applied with as much advantage as a solid wrench. I have bad it in view to unite sleadiness with conveniency in making such an instrument; and flattering myself that I have obtained both, I am desiruus to communicate my invention to the Society, and have therefore sent an instrument on the principle I have actually used, and which has met with the approbation of my employers and other persons.

This wrench, by means of a nut and screw, is adjusted with the greatest ease to the exact size required, and in that state rendered so steady that in use it is found equal to a solid wrench.

I have, for several years, been intrusted with the care and repairs of many valuable engines of various descriptions,

* From Transacions of the Society for the Encouragement of Arts, Maruw factire's and Commerce, for 1808.—Five guineas were voted to Mr. Barlow for this communication. 
composing the block machinery in this dock-yard, and I have always considered it as an object of great importance, for the preservation and neat appearance of engines, to attend to all the means which would obtain these advantages, and such, I think, will arise from the use of my universal wrench.

It is, perhaps, unnecessary to point out, that a wrench on this principle may be varied in its form and size, so as to be rendered probably more convenient for some particular purposes for which such instruments are required.

I am, sir, your obedient servant,

Portsmouth Dock Yard,

WM. BARLOW.

March 1, 1808.

To C. TaYlor, M.D. Sec.

Reference to the Engraving of $M r$. BaRLow's Improved Wrench. See Plate XIII. Figs. 5, 6, and 7.

This instrument is represented in Plate XIII. Fig. $s$ is a perspective view of it; fig. 6 a section of its head; and fig. 7 an external representation of the head. The screw head or nut to be turned is held between two jaws, one of which $a b d e$ is forged in the same piece with the bandle $\mathrm{A} \mathrm{A}$, the other, $f g$, is moveable between two chukes, and fastened to the fixed jaw by the strong screw $i$, which is tixed to the same jaw, passes through the moveable one, as shown in the section fig. 6 , and has a nut screwed upon it; the other screw, $h$, is tapped through the moveable $j a w$, and its point presses upon the bottom of a cavity made in the fixed jaw shown at $m$ in the section fig. 6 . To make the wrench fit any particular screw head or nut, the nut upon the strong screw $i$ must first be loosened, and the screw $h$ screwed in or out of the moveable jaw, until the opening $l g$ is just the proper width to receive the screw head or nut to be turned by the wrench; the nut of the screw $i$ is then to be screwed down, until it presses upon the jaw, and holds it perfectly tight. 

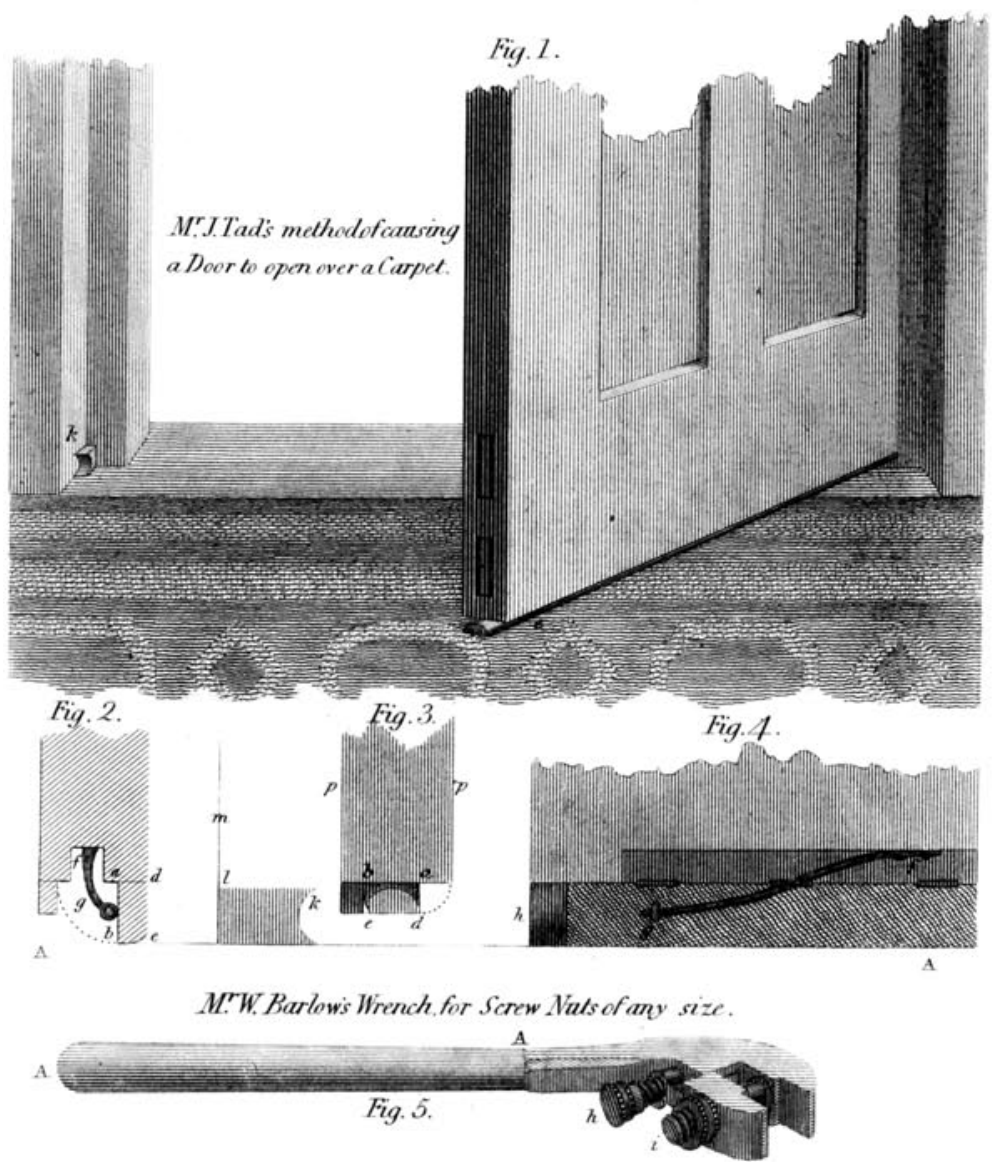

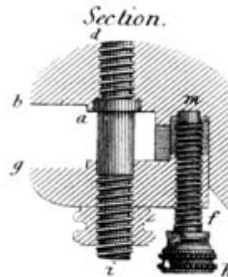

Fig. 6 .
Finlarged view of the Head.

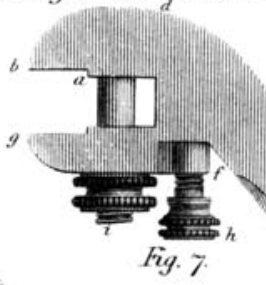

